\title{
WHY ARE SOME PEOPLE OPTIMISTIC WHILE OTHERS ARE NOT?
}

\author{
Lilly E. Both \\ Department of Psychology, University of New Brunswick (Canada)
}

\begin{abstract}
The purpose of this study was to examine factors that predict optimism and pessimism. Optimism, or positive bias, is the belief that undesirable events are more likely to happen to other people, than to oneself. Pessimism, on the other hand, is the belief that negative life events are more likely to happen to oneself. Although pessimism and optimism are inversely related, they are not opposite ends of the same continuum and should be measured separately. In this study, both dispositional traits (personality) and situational influences (coping styles) were examined in relation to optimism and pessimism. The sample consisted of 178 individuals $(\mathrm{M}$ age $=23.00 ; \mathrm{SD}=6.27$; range $=19-50$ years; $79 \%$ women $)$ who completed an online survey. Participants completed the BFI-2 to assess personality, the Ways of Coping Scale to determine coping styles, and the Future Events Scales to measure optimism and pessimism. The results found a moderate negative correlation between optimism and pessimism, suggesting that although these constructs are related, they are still distinct. A hierarchical multiple regression analysis was conducted using optimism as the criterion variable. The overall model was statistically significant and accounted for $42 \%$ of the variance in optimism scores. Significant predictors were lower scores on negative emotionality (neuroticism), and higher scores on extraversion, agreeableness and conscientiousness. As well, problem-focused coping made a unique contribution. Thus, optimists are emotionally stable individuals who are outgoing and sociable, easy to get along with, and responsible. They also are more likely to cope with a stressor by dealing directly with it. A second hierarchical multiple regression analysis was conducted using pessimism as the criterion variable, and again, the overall model was statistically significant, with $36 \%$ of the variance accounted for. However, a different pattern emerged with respect to the predictors. In this case, pessimism was predicted by age (being older), gender (being female), and higher negative emotionality (neuroticism) scores. Also, higher scores on emotion-focused coping contributed to the model. Pessimists, therefore, tend to be older and have more life experiences under their belts. They also tend to be women who are more anxious and depressed, and tend to put off dealing with stressors, which may not diffuse the situation. Taken together, these results suggest that our perceptions - whether we have a positive or negative bias - are influenced by both dispositional factors (like personality) and situation influences (like coping).
\end{abstract}

Keywords: Personality, coping, optimism, pessimism, positive bias.

\section{Introduction}

The optimistic bias occurs when an individual believes an undesirable event is more likely to happen to someone else than to oneself (Shepperd, Waters, Weinstein, \& Klein, 2015). Past research has focused on documenting the events for which the optimistic bias occurs, such as health risks like a fatal heart attack (Radcliffe \& Klein, 2002), or addiction to cigarette smoking and alcohol (Masiero, Riva, Oliveri, Fioretti \& Pravettoni, 2018), as well as environmental disasters such as hurricanes (Trumbo, Meyer, Marlatt, Peek \& Morrisey, 2014), and even chance events (Weinstein, 1980). Other studies have focused on the cognitive and motivational reasons for the distortion (Weinstein, 1980), as well as the consequences (both harmful and beneficial) of having a positive bias (Shepperd, Pogge, \& Howell, 2017).

Optimists tend to be more resilient (Davis \& Asliturk, 2011) and report using active coping in stressful situations (Carver et al., 1993). Pessimists, who believe negative life events are more likely to happen to themselves than to others, report using more escape strategies (Carver et al., 1993). Thus coping mechanisms play a role in the perceived risk of positive and negative life events. These strategies are considered a situational influence because they are learned and are amenable to change. 
Despite the large database on the pervasiveness of the optimistic bias, few studies to date have focused on dispositional influences such as personality. In one study, Borkenau and Mauer (2006) found personality influenced risk estimates. However, the authors only examined neuroticism and extraversion in their model of positive and negative emotionality. Personality is generally examined using the five factor model, namely the traits of neuroticism, extraversion, openness, conscientiousness and agreeableness (Costa \& McCrae, 1992). This study extended the literature by examining all five personality factors and coping styles in relation to the optimistic and pessimistic bias.

\subsection{Purpose of the present study}

The purpose of this study was to examine factors that predict optimism and pessimism. Both dispositional factors (personality) and situational influences (coping styles) were assessed.

\section{Method}

\subsection{Participants}

The sample consisted of 178 individuals $(M$ age $=23.00 ; S D=6.27$; range $=19-50$ years; $79 \%$ women) who completed an online survey. Although the survey was open to members from the general public, the vast majority of them were university students who were informed of the study through SONA, an online recruiting tool. The majority of participants were single $(85 \%$ single; $12 \%$ married or common law; 3\% divorced) and Caucasian (86\% White or Caucasian, $7 \%$ Asian, 2\% Black or African American; 5\% Other). University students could earn one bonus point towards their final grade for participating in this research. As well, all participants had the opportunity to be entered into a draw for a \$50 Amazon gift card (i.e., they sent an email at the completion of the study that was separate, and not linked to their data).

\subsection{Measures}

Demographic Questionnaire. This brief measure asked participants to report their age, gender, marital status, race/ethnicity, and education level.

The Big Five Inventory - 2 (BFI-2; Soto \& John, 2017). This measure consists of 60 items (some reverse coded) that assess personality factors commonly known as the Big Five - extraversion, agreeableness, conscientiousness, negative emotionality (neuroticism), and open-mindedness. Participants indicate the extent to which they agree or disagree with each statement on a 5 point scale where $1=$ disagree strongly and $5=$ agree strongly. This inventory is used widely in personality research, due to its established reliability and validity (Soto and John, 2017). In the present study, the subscale or factor scores had excellent reliability (Cronbach's $\mathrm{a}=.87$ extraversion; .80 agreeableness; .79 conscientiousness; .91 negative emotionality; and .76 open-mindedness).

The Ways of Coping Checklist (Vitaliano, Russo, Carr, Maiuro, \& Becker, 1985). This scale is a 42 item self-report measure that asks participants to assess their coping strategies in stressful situations. Participants rate the degree (from $0=$ not used to $3=$ used a great deal) to which they used certain strategies such as "blamed yourself" or "talked to someone who could do something about the problem." Three subscale scores are computed that assess problem-focused coping (15 items), emotion-focused coping (21 items), and seeking support (6 items). In the present study, only the problem- and emotion-focused subscales were utilized. This scale has good reliability and validity scores (see Vitaliano et al., 1985 for details). In the present study, Cronbach's a $=.87$ for problem-focused coping, and .90 for emotion-focused coping.

The Future Events Scale (Wichman, Reich, \& Weary, 2006). This scale consists of 23 items (the original scale had 26 items but new factor structure has dropped 3 items; see Wichman et al., 2006). Participants indicate the likelihood (on a scale from -5 extremely unlikely to +5 extremely likely) that certain events (such as "to have a loved one die in the next year") will happen to them. Two subscale scores were computed - one for optimism (Cronbach's $a=.88$ ) and one for pessimism (Cronbach's a =.81).

\subsection{Procedure}

All participants were directed to Qualtrics, an online survey platform. Participants read a consent form describing the nature of the study, and indicated whether they wished to participate by either clicking on the consent button or exiting the survey. Once inside the survey, the demographic measure was always presented first, followed by the remaining measures in random order. The survey took approximately 20 minutes to complete. 


\section{Results}

\subsection{Gender differences}

Independent samples $t$-tests were conducted to determine if there were any gender differences. Women scored higher than men on negative emotionality (neuroticism; $M$ women $=3.25, S D=.87$; $M$ men $=2.41, S D=.60 ; t=-6.56, p<.001)$, on emotion-focused coping $(M$ women $=2.50, S D=.59$; $M$ men $=2.21, S D=.40 ; t=-3.32, p=.001)$ and on pessimism $(M$ women $=5.55, S D=1.65$; $M$ men $=4.77, S D=1.62 ; t=-2.46, p=.015)$.

\subsection{Correlations}

The bivariate correlations are presented in Table 1. Age was correlated with open-mindedness, agreeableness, and pessimism (older adults scored higher on these measures). Negative emotionality (neuroticism) was correlated positively with emotion-focused coping and pessimism, and was negatively correlated with problem-focused coping and optimism. The remaining personality factors, by and large, showed the opposite pattern in that they correlated positively with problem-focused coping and optimism, and correlated negatively with emotion-focused coping and pessimism. There was no statistically significant correlation between problem-focused and emotion-focused coping. However, problem-focused coping was correlated positively with optimism, whereas emotion-focused coping correlated negatively with optimism and positively with pessimism. Finally optimism and pessimism were inversely and only moderately correlated.

Table 1. Bivariate Correlations with Age, Personality Factors, Coping and Optimism.

\begin{tabular}{|c|c|c|c|c|c|c|c|c|c|}
\hline & $\mathrm{N}$ & $\mathrm{E}$ & $\mathrm{O}$ & $\mathrm{A}$ & $\mathrm{C}$ & PFC & EFC & OPT & PES \\
\hline Age & -.04 & .04 & $.19 *$ & $.18 *$ & .05 & .11 & -.10 & -.04 & $.15^{*}$ \\
\hline $\mathrm{N}$ & & $-.42 * * *$ & -.01 & $-.33 * * *$ & $-.26 * * *$ & $-.27 * * *$ & $.52 * * *$ & $-.40 * * *$ & $.50 * * *$ \\
\hline $\mathrm{E}$ & & & $.22 * *$ & .15 & $.24 * *$ & $.22 * *$ & $-.27 * * *$ & $.47 * * *$ & $-.32 * * *$ \\
\hline $\mathrm{O}$ & & & & $.21 * *$ & $.20 * *$ & $.22 * *$ & $-.16 *$ & $.21 * *$ & -.07 \\
\hline $\mathrm{A}$ & & & & & $.43 * * *$ & $.19 *$ & $-.30 * * *$ & $.33 * * *$ & $-.26 * * *$ \\
\hline $\mathrm{C}$ & & & & & & $.35 * * *$ & $-.30 * * *$ & $.38 * * *$ & $-.23 * *$ \\
\hline PFC & & & & & & & -.04 & $.43 * * *$ & -.11 \\
\hline EFC & & & & & & & & $-.28 * * *$ & $.44 * * *$ \\
\hline OPT & & & & & & & & & $-.40 * * *$ \\
\hline
\end{tabular}

$\mathrm{N}$ is Negative Emotionality, $\mathrm{E}$ is Extraversion, $\mathrm{O}$ is Open-Mindedness, A is Agreeableness, C is Conscientiousness, PFC is problem-focused coping, EFC is emotion-focused coping, OPT is optimism, PES is pessimism

\subsection{Hierarchical regression analyses}

A hierarchical regression analysis was conducted to determine whether personality and coping strategies predicted optimism. Age and gender were entered on the first step to control for their effects. On the second step, the five personality factors were added. Finally, on the third step, the two coping strategies were added. Tolerance and VIF (variance inflation factor) were all within acceptable levels for the analysis. The overall model was statistically significant and accounted for $42 \%$ of the variance $(F(9,165)=13.34, p<.001$, multiple $R=.65)$. Age and gender were not statistically significant predictors $\left(F(2,172)=1.47, p=.23, R^{2}=.02\right)$. The five personality factors were entered on the second step and produced a statistically significant change in the model $\left(R^{2}\right.$ change $\left.=.34, F_{\text {inc }}(5,167)=17.48, p<.001\right)$. Significant predictors were Negative Emotionality (neuroticism) $\left(\beta=-.17, t=-2.17, p=.03, s r^{2}=.02\right)$, Extraversion $\left(\beta=.31, t=4.29, p<.001, s r^{2}=.07\right)$, Agreeableness $\left(\beta=.15, t=2.08, p=.04, s r^{2}=.02\right)$, and Conscientiousness $\left(\beta=.19, t=2.61, p=.01, s r^{2}=.03\right)$. Finally, the coping strategies were entered on the last step and produced a statistically significant change in the model $\left(R^{2}\right.$ change $=.07$, $\left.F_{\text {inc }}(2,165)=9.50, p<.001\right)$. The only significant predictor at this step was problem-focused coping $\left(\beta=.29, t=4.36, p<.001, s r^{2}=.07\right)$. The adjusted $R^{2}$ value of .39 in the overall model indicates that more than a third of the variability in optimism scores was predicted by personality traits and coping, namely lower scores on negative emotionality (neuroticism), and higher scores on extraversion, agreeableness, conscientiousness, and problem-focused coping.

A second hierarchical regression analysis was conducted using pessimism as the criterion variable. Again, tolerance and VIF were within acceptable limits for the analysis. The overall model was statistically significant and accounted for $36 \%$ of the variance $(F(9,165)=10.23, p<.001$, multiple 
$R=.60)$. The first step of the model was statistically significant $\left(F(2,172)=7.42, p=.001, R^{2}=.08\right)$. Significant predictors were age $\left(\beta=.17, t=2.31, p=.02, s r^{2}=.03\right)$ and gender $(\beta=.24, t=3.25$, $\left.p=.001, s r^{2}=.06\right)$. The five personality factors were entered on the second step and produced a statistically significant change in the model $\left(R^{2}\right.$ change $\left.=.24, F_{\text {inc }}(5,167)=11.80, p<.001\right)$. The significant predictor at this stage was Negative Emotionality (neuroticism) $(\beta=.37, t=4.59$, $\left.p<.001, s r^{2}=.09\right)$. Finally, the coping strategies were entered on the last step and produced a statistically significant change in the model $\left(R^{2}\right.$ change $\left.=.04, F_{\text {inc }}(2,165)=4.93, p=.008\right)$. The only significant predictor at this step was emotion-focused coping $\left(\beta=.24, t=2.97, p=.003, s r^{2}=.04\right)$. The adjusted $R^{2}$ value of .32 in the overall model indicates that a third of the variability in pessimism scores was predicted by being older, being female, having higher negative emotionality (neuroticism) scores, and using emotion-focused coping strategies.

\section{Discussion}

Why are some people optimistic while others are not? This study examined dispositional factors (personality traits) and situational influences (coping styles) to examine this question.

In this study, optimism was predicted by personality traits and coping, namely lower scores on negative emotionality (neuroticism), and higher scores on extraversion, agreeableness, conscientiousness, and problem-focused coping. However, the largest proportion of variance was explained by the personality factors, with extraversion contributing the most unique variance. Extraverts are sociable, assertive and have high energy levels (Soto \& John, 2017). Indeed, extraverts have been described as optimistic (Costa \& McCrae, 1992).

Pessimism was predicted by age (being older), gender (being female), having higher negative emotionality (neuroticism) scores, and using emotion-focused coping. Again, the largest proportion of variance was explained by personality factors, namely negative emotionality. Negative emotionality is comprised of three subscales: anxiety, depression and emotional volatility (Soto \& John, 2017). These characteristics are associated with maladjustment and individuals high on negative emotionality tend to experience more negative affective states and do not cope well in the face of adversity (Costa \& McCrae, 1992). As well, women tend to score higher than men on neuroticism (Costa \& McCrae, 1988; Fowler $\&$ Both, 2017) and on the use of emotion-focused coping strategies (Eaton \& Bradley, 2008). However, in this study, the gender difference should be interpreted with caution given the majority of participants were women.

Optimism and pessimism were measured separately in this study and were inversely but only moderately correlated. However, for both the optimistic and pessimistic bias, personality factors accounted for the lion's share of the variance. These results underscore the importance of assessing personality. Personality is considered a dispositional trait that is relatively stable over the adult years (Costa \& McCrae, 1988). One's personality can be viewed as a lens through which one perceives and interprets the world. Individuals who are extraverts, agreeable and conscientious experience their world differently than those who live their lives with high anxiety and depression.

Both problem-focused and emotion-focused coping strategies were assessed in this study. Interestingly, the two coping styles were not correlated, but differentially predicted the outcome variables. Problem-focused coping - dealing directly with a stressor by problem-solving solutions - predicted optimism, whereas pessimism was predicted by emotion-focused coping, such as blaming oneself or wishful thinking. Coping styles have been targeted in interventions (Powell, Wegmann, \& Shin, 2019) and respond well to therapy. Thus, in order to address the pessimistic bias, therapists should focus on influences that are amenable to change.

\section{Conclusion}

Who are optimists? They are emotionally stable individuals who are cheerful and friendly, easy to get along with, and reliable. They are also more likely to cope with a stressor by facing it directly. Pessimists, on the other hand, tend to be older individuals who, by definition, have more life experiences under their belts. Perhaps they are disillusioned by the cumulative effect of long-term, everyday frustrations. They tend to be women and are more anxious, depressed, and emotionally volatile. Pessimists also tend to put off dealing with stressors, which may not diffuse the situation. Wishing something will go away does not make it happen. The bottom line is that our perceptions - whether we have a positive or negative bias - are influenced by both dispositional factors (like personality) and situational influences (like coping). 


\section{References}

Borkenau, P., \& Mauer, N. (2006). Personality, emotionality and risk perception. Journal of Individual Differences, 27(3), 127-135.

Carver, C.S., Pozo, C., Harris, S.D., Noriega, V., Scheier, M.F., Robinson, D.S., ... Clark, K.C. (1993). How coping mediates the effect of optimism on distress: A study of women with early stage breast cancer. Journal of Personality and Social Psychology, 65(2), 375-390.

Costa, P.T., \& McCrae, R.R. (1988). Personality in adulthood: A six-year longitudinal study of self-reports and spouse ratings on the NEO Personality Inventory. Journal of Personality and Social Psychology, 54(5), 853-863.

Costa, P.T., \& McCrae, R.R. (1992). Revised NEO Personality Inventory (NEO-PI-R) and NEO Five Factor Inventory (NEO-FFI) professional manual. Odessa, FL: Psychological Assessment Resources.

Davis, C.G., \& Asliturk, E. (2011). Toward a positive psychology of coping with anticipated events. Canadian Psychology, 52(2), 101-110.

Eaton, R.J., \& Bradley, G. (2008). The role of gender and negative affectivity in stressor appraisal and coping selection. International Journal of Stress Management, 15(1), 94-115.

Fowler, S. A., \& Both, L. E. (2017). The influence of personality and copying styles on forgiveness. In C. Pracana \& M. Wang (Eds.), Psychology application \& developments III (pp. 109-120). Lisbon: inScience Press.

Masiero, M., Riva, S., Oliveri, S., Fioretti, C., \& Pravettoni, G. (2018). Optimistic bias in young adults for cancer, cardiovascular and respiratory diseases: A pilot study on smokers and drinkers. Journal of Health Psychology, 23(5), 645-656.

Powell, T. M., Wegmann, K. M., \& Shin, O. J. (2019, February 7). Stress and coping in social service providers after superstorm Sandy: An examination of a postdisaster psychoeducational intervention. Traumatology. Advance online publication. http://dx.doi.org/10.1037/trm0000189

Radcliffe, N.M., \& Klein, W.M.P. (2002). Dispositional, unrealistic, and comparative optimism: Differential relations with the knowledge and processing of risk information and beliefs about personal risk. $P S P B, 28(6), 836-846$.

Shepperd, J. A., Pogge, G., Howell, J.L. (2017). Assessing the consequences of unrealistic optimism: Challenges and recommendations. Consciousness and Cognition, 50, 69-78.

Shepperd, J.A., Waters, E.A., Weinstein, N.D., \& Klein W.M.P. (2015). A primer on unrealistic optimism. Current Directions in Psychological Science, 24(3), 232-237.

Soto, C.J., \& John, O.P. (2017). The next Big Five Inventory (BFI-2): Developing and assessing a hierarchical model with 15 facets to enhance bandwidth, fidelity, and predictive power. Journal of Personality and Social Psychology, 113(1), 117-143.

Trumbo, C., Meyer, M.A., Marlatt, H., Peek, L., \& Morrisey, B. (2014). An assessment of change in risk perception and optimistic bias for hurricanes among gulf coast residents. Risk Analysis, 34(6), 1013-1024.

Vitaliano, P.P., Russo, J., Carr, J.E., Maiuro, R.D., \& Becker, J. (1985). The Ways of Coping Checklist: Revision and psychometric properties. Multivariate Behavioral Research, 20(1), 3-26.

Weinstein, N.D. (1980). Unrealistic optimism about future life events. Journal of Personality and Social Psychology, 39(5), 806-820.

Wichman, A.L., Reich, D.A., \& Weary, G. (2006). Perceived likelihood as a measure of optimism and pessimism: Support for the Future Events Scale. Psychological Assessment, 18, 215-219. doi: 10.1037/1040-3590.18.2.215 